\title{
Simulations support the interaction of the SARS-CoV-2 spike protein with nicotinic acetylcholine receptors
}

\author{
A. Sofia F. Oliveira, ${ }^{a}$ Amaurys Avila Ibarra, ${ }^{\mathrm{b}}$ Isabel Bermudez, ${ }^{\mathrm{c}}$ Lorenzo Casalino, ${ }^{\mathrm{d}}$ Zied Gaieb, ${ }^{\mathrm{d}}$ \\ Deborah K. Shoemark, ${ }^{\mathrm{e}}$ Timothy Gallagher, ${ }^{\mathrm{a}}$ Richard B. Sessions, ${ }^{\mathrm{e}}$ Rommie E. Amaro ${ }^{\mathrm{d}}$ and Adrian J. \\ Mulholland $\mathrm{a}^{\mathrm{*}}$
}

${ }^{a}$ Centre for Computational Chemistry, School of Chemistry, University of Bristol, Bristol BS8 1TS, UK
${ }^{\mathrm{b}}$ Research Software Engineering, Advanced Computing Research Centre, University of Bristol, Bristol BS1 5QD, UK

${ }^{\mathrm{c}}$ Department of Biological and Medical Sciences, Oxford Brookes University, Oxford OX30BP, UK

${ }^{\mathrm{d}}$ Department of Chemistry and Biochemistry, University of California San Diego, La Jolla, CA, 92093 USA

${ }^{\text {e }}$ School of Biochemistry, University of Bristol, Bristol BS8 1DT, UK

*Corresponding author(s): adrian.mulholland@bristol.ac.uk

\begin{abstract}
Changeux et al. recently suggested that the SARS-CoV-2 spike (S) protein may interact with nicotinic acetylcholine receptors (nAChRs). Such interactions may be involved in pathology and infectivity. Here, we use molecular simulations of validated atomically detailed structures of nAChRs, and of the S protein, to investigate this 'nicotinic hypothesis'. We examine the binding of the Y674-R685 loop of the $\mathrm{S}$ protein to three nAChRs, namely the human $\alpha 4 \beta 2$ and $\alpha 7$ subtypes and the muscle-like $\alpha \beta \gamma \delta$ receptor from Tetronarce californica. Our results indicate that Y674-R685 has affinity for nAChRs and the region responsible for binding contains the PRRA motif, a four-residue insertion not found in other SARS-like coronaviruses. In particular, R682 has a key role in the stabilisation of the complexes as it forms interactions with loops A, B and C in the receptor's binding pocket. The conformational behaviour of the bound Y674-R685 region is highly dependent on the receptor subtype, adopting extended conformations in the $\alpha 4 \beta 2$ and $\alpha 7$ complexes and more compact ones when bound to the
\end{abstract}


muscle-like receptor. In the $\alpha 4 \beta 2$ and $\alpha \beta \gamma \delta$ complexes, the interaction of Y674-R685 with the receptors forces the loop $\mathrm{C}$ region to adopt an open conformation similar to other known $\mathrm{nAChR}$ antagonists. In contrast, in the $\alpha 7$ complex, Y674-R685 penetrates deeply into the binding pocket where it forms interactions with the residues lining the aromatic box, namely with $\operatorname{TrpB}, \operatorname{TyrC} 1$ and $\operatorname{TyrC} 2$. Estimates of binding energy suggest that Y674-R685 forms stable complexes with all three nAChR subtypes. Analyses of the simulations of the full-length S protein show that the Y674-R685 region is accessible for binding, and suggest a potential binding orientation of the $\mathrm{S}$ protein with $\mathrm{nAChRs}$.

\section{Main text}

The severe acute respiratory syndrome coronavirus-2 (SARS-CoV-2) is a novel strain of coronavirus that first appeared in China in late 2019 and causes the potentially fatal disease COVID-19. This virus initially infects respiratory epithelial cells by binding to the angiotensin-converting 2 enzyme ${ }^{1}$ (ACE2) and may cause pneumonia and severe acute respiratory distress syndrome. ${ }^{2,3}$ Since it emerged as a human pathogen, SARS-CoV-2 has caused more than 27.5 million confirmed cases of COVID-19 and 903,756 deaths worldwide as of $9^{\text {th }}$ September, $2020 .{ }^{4}$ Several major risk factors for the development of COVID-19 have been identified, namely age, heart disease, diabetes and hypertension. ${ }^{5}$ Recently, given the apparently low prevalence of smokers among hospitalised COVID-19 patients, ${ }^{6-8}$ it was proposed that nicotine may offer some protective value to mitigate COVID-19 (the 'protection' hypothesis). ${ }^{6}$ It has been suggested that medicinal nicotine (either in patches, gum, or electronic delivery systems) should be investigated as a therapeutic option for this disease. ${ }^{6,9}$ Clinical trials for nicotine are underway (e.g. https://clinicaltrials.gov/ct2/show/NCT04429815). It should be noted that alternative explanations to the 'protection' hypothesis have been proposed: ${ }^{10}$ the first relates to the failure in correctly identifying smokers upon hospital admission, ${ }^{10}$ and the second is that hospitalised COVID-19 patients may be less likely to smoke as their comorbidities motivate them to quit ('smoking cessation' hypothesis). ${ }^{10}$

Based on the early observations of the lower than expected smoking prevalence in hospitalised COVID19 patients, Changeux and colleagues suggested a role for nicotinic acetylcholine receptors (nAChRs) in the pathophysiology of COVID-19 via a direct interaction between these receptors and the viral spike (S) glycoprotein. ${ }^{11}$ This suggestion was based in the fact that the $\mathrm{S}$ protein from SARS-CoV-2 contains a sequence motif similar to known nAChR antagonists ${ }^{11}$ (Figure S1), such as $\alpha$-bungarotoxin from Bungarus multicinctus and glycoprotein from Rabies lyssavirus (formerly Rabies virus). Changeux et al. also proposed that COVID-19 might be controlled or mitigated by the use of nicotine, if the latter can sterically or allosterically compete with the virus for binding to these receptors. ${ }^{9,11}$ 
nAChRs are cation channels that belong to the pentameric ligand-gated ion channel family. ${ }^{12}$ They are present in both the peripheral (at the skeletal neuromuscular junction and in the autonomic nervous system) and central nervous system (CNS). ${ }^{13}$ The neuronal receptors have emerged as important targets for the treatment of Alzheimer's disease, schizophrenia, pain and nicotine addiction. ${ }^{13,14}$ Mutations of muscle nAChR can cause congenital myasthenia gravis. ${ }^{4}$ There is a large repertoire of nAChR subtypes which differ in the homo- or heteromeric assembly of five monomers arranged around a central channel axis. ${ }^{15-17}$ Each subtype shows different selectivity for agonists and antagonists. ${ }^{15-17}$ All nAChRs share the same basic architecture (Figure 1B), formed of a large N-terminal extracellular domain (ECD), where the agonist binding site is located; a transmembrane domain (TMD) surrounding the ion channel; an intracellular domain (ICD); and a short extracellular C-terminal domain (CTD). ${ }^{15-17}$ The ligandbinding pocket is located at the interface between two neighbouring subunits (Figure 1B) and is formed by loops A, B and C from the principal subunit and D, E and F from the complementary subunit (Figure S2).

According to Changeux et al.'s 'nicotinic hypothesis', direct interaction between SARS-CoV-2 and nAChRs is proposed to occur via a loop in the viral S protein ${ }^{11}$ (Figure S3). Here, we investigate this potential interaction for three nAChR subtypes, using fully solvated, all-atom molecular dynamics (MD) simulations. Our modelling (using atomically detailed structures of the glycosylated S protein, ${ }^{18}$ and the muscle-type nAChR from Tetronarce californica ${ }^{19}$ ) suggests that the association between the $\mathrm{S}$ protein and $\mathrm{nAChR}$ is not possible when the two proteins are parallel to each other but can be achieved in an orthogonal arrangement (Figure S3). The S protein from SARS-CoV-2 is a fusion protein ${ }^{20,21}$ found on the surface of the virion that mediates entry into host cells. It is an extensively glycosylated homotrimer with each monomer formed by three domains (Figure 1A): head, stalk and cytoplasmic tail (CT). ${ }^{21}$ The head comprises two subunits: S1 is responsible for binding to ACE2 of the host cell, ${ }^{21}$ and S2 for membrane fusion. ${ }^{21}$ The SARS-CoV-2 S protein contains two proteolytic cleavage sites: ${ }^{21}$ one ('furin cleavage' site) at the S1/S2 boundary thought to activate the protein ${ }^{22}$ and a second in the S2 subunit that releases the fusion peptide. ${ }^{23}$ The loop suggested by Changeux et al. to be directly involved in the interaction with nAChRs spans from Y674 to R685 and is located in the head region of the protein, at the interface between the S1 and S2 domains, immediately preceding the S1/S2 cleavage point ${ }^{21}$ (Figure 1A). Furin cleaves the peptide bond after R685, thus separating it from its neighbour S686 (e.g. before viral exit from the host cell). ${ }^{22}$ Cleavage activation of viral glycoproteins is known to be important for infectivity and virulence. ${ }^{21,22}$ Analysis of the dynamics of Y674-R685 in MD simulations of the full-length glycosylated SARS-CoV-2 S protein $^{18}$ (see Supporting Information) reveals that the furin loop region is only weakly shielded by the glycans, and predominantly solvent exposed, especially when the S protein is in the closed state (Figure S4). In these simulations, Y674-R685 shows a different extent of conformational flexibility according to the state (open or closed) of the S protein, which might allude to a different binding propensity. This is most likely a structural consequence of the S protein's 
bioRxiv preprint doi: https://doi. org/10.1101/2020.07.16.206680; this version posted September 14,2020. The copyright holder for this preprint (which was not certified by peer review) is the author/funder, who has granted bioRxiv a license to display the preprint in perpetuity. It is made available under aCC-BY-NC-ND 4.0 International license.

receptor binding domain transitioning between the two states, which ultimately affects the packing of the three monomers. However, the peptide is found to adopt conformations potentially compatible with binding to nAChRs (Figure S5).

The Y674-R685 region contains the 4-residue PRRA insertion not present in other SARS-CoV-related coronaviruses, ${ }^{24}$ and includes a sequence motif homologous to several neurotoxins known to target nAChRs. ${ }^{11}$ In SARS-CoV-2, abrogation of the PRRA motif moderately affects virus entry into cells. ${ }^{21,22}$ This motif has recently been shown experimentally to interact with neuropilin-1 receptors ${ }^{25}$ and has also been suggested to have an affinity for $\mathrm{T}$ cell receptors. ${ }^{26}$ The high sequence similarities between Y674-R685 region and several known nAChR antagonists (Figure S1) suggests that this region of the SARS-CoV-2 S protein may bind to nAChRs, and could potentially act as an antagonist thus inhibiting gating. ${ }^{11}$ Hence, it has been postulated that nicotine may have an effect in COVID-19 by competing and interfering with this binding. Note that very recently an alternative region (G381 to K386 in the S1 subunit) in the S protein has been hypothesized to interact with nAChRs. ${ }^{27}$
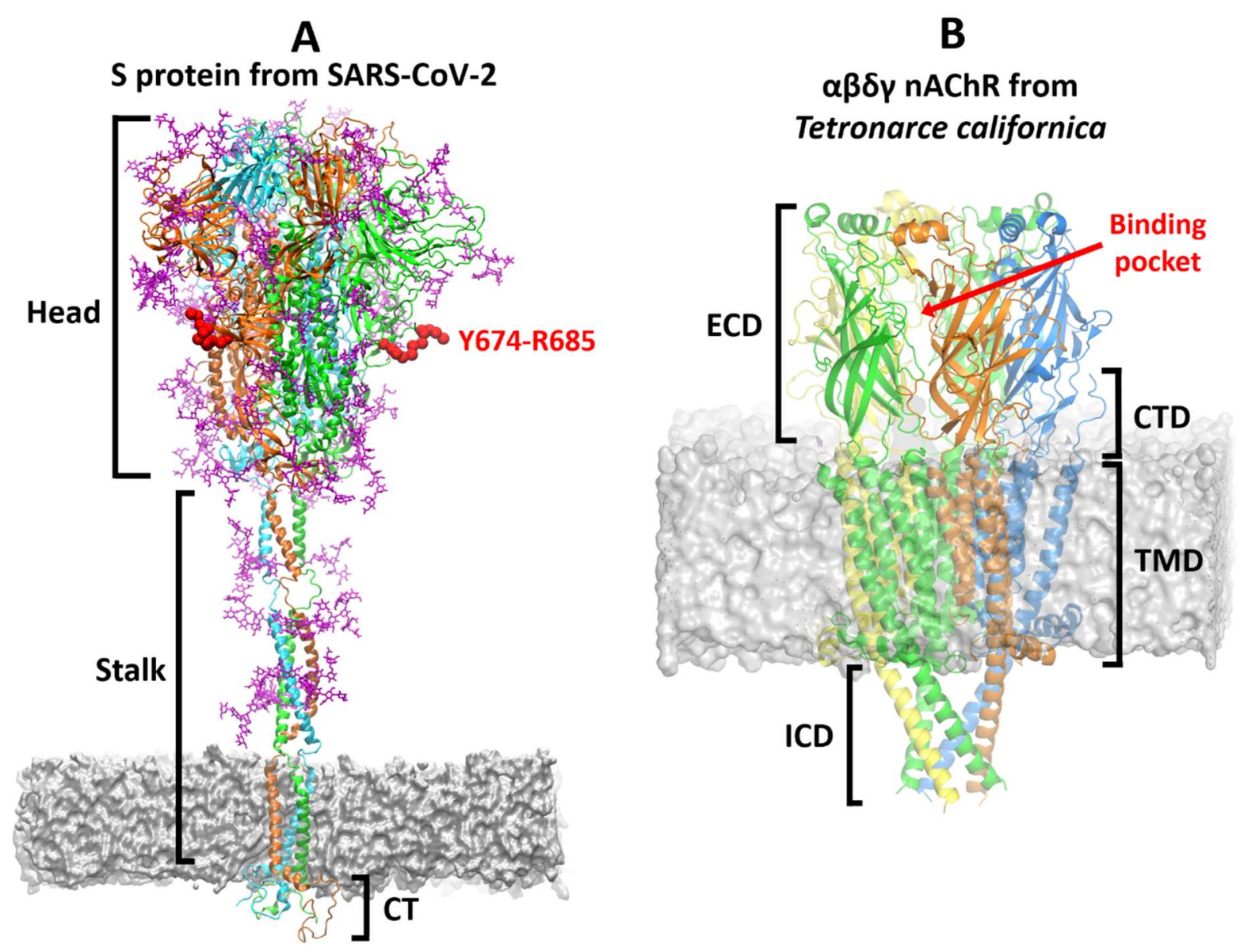

Figure 1. Overview of the three-dimensional structures of the S protein from SARS-CoV-2 and the $\alpha \beta \gamma \delta$ nAChR from Tetronarce californica. (A) The model for the complete, fully glycosylated, SARS-CoV-2 S 
protein represents the closed state of the protein, after furin cleavage. ${ }^{18}$ The S protein is a homotrimer. ${ }^{21}$ each monomer is shown in a different colour, namely green, cyan and orange, with glycans depicted in pink. Each monomer is formed by three domains: head, stalk and cytoplasmic tail (CT). ${ }^{21}$ The Y674-R685 region is shown in red. In MD simulations of the glycosylated SARS-CoV-2 S protein, ${ }^{18}$ Y674-R685 is accessible, being only weakly shielded by the glycans (Figure S4) and also shows high flexibility (Figure S5). (B) The cryoEM structure of the muscle-type receptor from Tetronarce californica (PDB code: 6UWZ). ${ }^{19}$ This receptor is a heteropentamer formed of two $\alpha$ (green), one $\beta$ (blue), one $\delta$ (yellow), and one $\gamma$ (orange) subunits. Each monomer is formed by four domains: ${ }^{15-17}$ extracellular (ECD), transmembrane (TMD), intracellular (ICD) and C-terminal domain (CTD). The agonist binding site is located in the ECDs at the interface between two neighbouring subunits.

Here, we use molecular simulation to examine the nicotinic hypothesis proposed by Changeux et al. ${ }^{11}$ of whether the SARS-CoV-2 S protein can bind stably to nAChRs via the Y674-R685 region. To test this, we built structural models for the complexes formed by the 12-residue region from the $\mathrm{S}$ protein (S-peptide) and the ECDs of three different nAChRs, namely the human $\alpha 4 \beta 2$, human $\alpha 7$ and musclelike $\alpha \beta \gamma \delta$ receptor from Tetronarce californica (hereafter named $\alpha \beta \gamma \delta$ ). These simulations build on our successful previous extensive simulations of $\mathrm{nAChRs,} \mathrm{which} \mathrm{have} \mathrm{e.g.} \mathrm{identified} \mathrm{a} \mathrm{general} \mathrm{mechanism}$ for signal propagation in this receptor family. ${ }^{28-30}$

The $\alpha 4 \beta 2 \mathrm{nAChR}$ is the most prevalent heteromeric subtype in the brain: it is implicated in diverse processes such as cognition, mood and reward, and is necessary for nicotine addiction. ${ }^{15-17,31}$ The homomeric $\alpha 7 \mathrm{nAChR}$ is also abundant and widely expressed in the CNS, where it contributes to cognition, sensory processing and attention. ${ }^{32}$ The $\alpha 7$ subtype is also expressed on a variety of nonneuronal cells, such as immune cells, astrocytes, microglia, endothelial cells, where it contributes to anti-inflammatory pathways. ${ }^{33-35}$ Due to its role in the downregulation of the production of proinflammatory cytokines, ${ }^{33-35}$ it has been suggested that the $\alpha 7 \mathrm{nAChR}$ may be involved in the hyperinflammation response that can be caused by SARS-CoV-2., ${ }^{9,36}$ The muscle-type receptor derived from the electric organ of Tetronarce californica (formerly Torpedo californica) is one the most extensively studied nAChRs, and has provided significant structural insight into this receptor family. It is formed by two $\alpha$ and one $\beta, \delta$ and $\gamma$ subunits and has high sequence similarity (55\%-80\% identity) with its human counterpart. ${ }^{37}$ For this reason, and because of the availability of structural information, we used it here as a proxy for the human muscle-type nAChRs. Muscle fatigue, myalgia and arthralgia are common symptoms in COVID-19 patients, but we are not aware of studies reporting the presence of SARS-CoV-2 in the skeletal muscles, joint, or bones. It is still unclear how the virus affects the musculoskeletal system. ${ }^{38}$

Structural models of the three SARS-CoV-2 S-peptide-nAChR complexes were built based on the cryoEM structure of the $\alpha \beta \gamma \delta$ receptor from Tetronarce californica with bungarotoxin. ${ }^{19} \alpha$ bungarotoxin is a neurotoxin that acts as a nAChR antagonist, directly competing with acetylcholine, ${ }^{39}$ 
bioRxiv preprint doi: https://doi.org/10.1101/2020.07.16.206680; this version posted September 14, 2020. The copyright holder for this preprint (which was not certified by peer review) is the author/funder, who has granted bioRxiv a license to display the preprint in perpetuity. It is made available under aCC-BY-NC-ND 4.0 International license.

and has high sequence similarity with the Y674-R685 region of the S protein of SARS-CoV-2 (Figure S1). Twenty models were generated for each complex, and the one with the lowest Modeller objective function ${ }^{40}$ (Figures 2 and S6) was used as the starting point for MD simulations (see the Supporting Information for more details). Three replicates, each $300 \mathrm{~ns}$ long, were performed for each complex to investigate the peptide-receptor conformational behaviour and possible induced-fit effects.
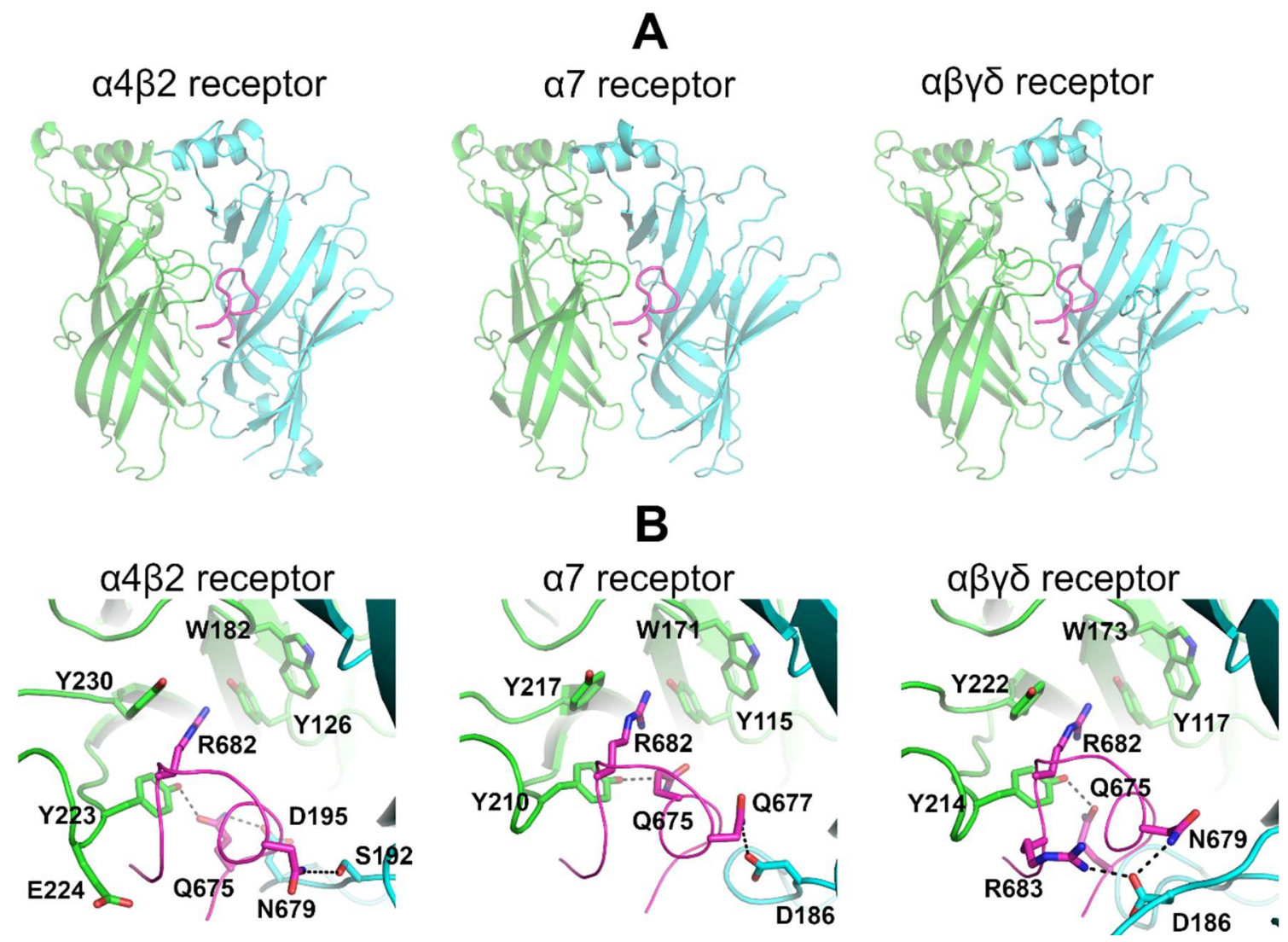

Figure 2. Predicted binding modes of the SARS-CoV-2 S-peptide to different nAChRs. (A) Complexes formed by the S-peptide and three different nAChRs, namely the human $\alpha 4 \beta 2$, human $\alpha 7$ and the muscle-like $\alpha \beta \gamma \delta$ receptor from Tetronarce californica. The S-peptide (region Y674-R685) is highlighted in magenta, and the principal and complementary subunits of the receptors are coloured in green and cyan, respectively. These models show the conformation of the S-peptide bound to the first pocket. In the human $\alpha 4 \beta 2$ receptor, the binding pocket is formed by one $\alpha 4$ and one $\beta 2$ subunit, whereas in the human $\alpha 7 \mathrm{nAChR}$, the pocket is formed by two $\alpha 7$ subunits. In the $\alpha \beta \gamma \delta$ receptor, the two binding pockets are non-equivalent: one is formed by an $\alpha$ and a $\delta$ and the second by an $\alpha$ and a $\gamma$ subunits. (B) Closeup view of the peptide-receptor interaction region. Residues involved in binding of the S-peptide are shown with sticks. Note that the sidechain of R682 in the S-peptide is located inside the aromatic box establishing cation- $\pi$ interactions with some of the highly conserved aromatic residues lining the pocket. Note also that all residue numbers used in this work, unless stated otherwise, refer to the human $\alpha 7$ (UniProt code P36544), human $\alpha 4$ (UniProt code P43681), human $\beta 2$ (UniProt code P17787), Tetronarce californica $\alpha$ (UniProt code P02710), Tetronarce californica $\delta$ (UniProt code P02718), Tetronarce californica $\gamma$ (UniProt code P02714) and SARS-CoV-2 S protein (Uniprot code P0DTC2) sequences. 
At the beginning of the simulations, the S-peptide was located in the binding pocket, bound by interactions with both the principal and complementary subunits (Figures 2 and S6). A closeup view of the peptide-receptor interface reveals extensive contacts (Figures 2B and S6B), mainly with the principal subunit. In all three complexes, the sidechain of R682 of the S-peptide binds as the recognised positively charged group, a strictly conserved pharmacophore of all nAChR ligands. ${ }^{41,42}$ As can be seen in Figure 2B, the guanidinium group of R682 is well-positioned inside the aromatic box, forming several cation- $\pi$ interactions with TyrC1 ( $\alpha 4 \mathrm{Y} 223, \alpha 7 \mathrm{Y} 210, \alpha \mathrm{Y} 214$ in the human $\alpha 4 \beta 2$, human $\alpha 7$ and muscle-like $\alpha \beta \gamma \delta$ receptor from Tetronarce californica, respectively), TyrC2 ( $\alpha 4 \mathrm{Y} 230, \alpha 7 \mathrm{Y} 217$, $\alpha Y 222)$ and TyrA ( $\alpha 4 Y 126, \alpha 7 Y 115, \alpha Y 117)$. Note that these cation- $\pi$ interactions do not entirely mimic the binding of nicotine as no interactions with $\operatorname{TrpB}$ are present. ${ }^{43} \mathrm{R} 682$ is part of the four-residue PRRA insertion not found in other SARS-like coronaviruses,${ }^{24}$ and it forms part of the furin cleavage site located the boundary between the S1 and S2 subunits. ${ }^{21}$ Additional binding interactions with the peptide are also observed with different residues depending on the receptor subtype: in the $\alpha 4 \beta 2$ $\mathrm{nAChR}$, hydrogen bonds involving the sidechains of $\alpha 4 \mathrm{Y} 223, \alpha 4 \mathrm{E} 224, \beta 2 \mathrm{~S} 192, \beta 2 \mathrm{D} 195$ in the receptor and Q675, N679 and the main-chain nitrogen of A684 of the S-peptide are observed; in the $\alpha 7 \mathrm{nAChR}$, two hydrogen bonds between $\alpha 7 \mathrm{D} 186$ and $\alpha 7 \mathrm{Y} 210$ in the receptor and S-peptide Q675 and Q677 are seen; in the $\alpha \beta \gamma \delta$ receptor from Tetronarce californica, hydrogen bonds involving $\alpha \mathrm{Y} 214$ and $\delta \mathrm{D} 186$ from the receptor and Q675, N679, R682 and R683 of the peptide are observed.

During the simulations, distinct patterns of dynamical behaviour were identified for the S-peptide in the different receptor subtypes. In the $\alpha 4 \beta 2$ and $\alpha 7$ complexes, the peptide showed high positional and conformational variability, while in the $\alpha \beta \gamma \delta$ complex, it generally remained in the same pose throughout the simulation (Figures S7 and S9). Similar behaviour is observed for the peptides in the two binding pockets in each complex. When bound to the $\alpha 4 \beta 2$ and $\alpha 7 \mathrm{nAChR}$, the peptide adopted many different binding modes inside the pocket, ranging from highly compact to fully extended conformations (Figure S9). In contrast, in the $\alpha \beta \gamma \delta$ receptor, the peptide was more compact (Figure S9). The range of the radius of gyration values for the S-peptide in all three complexes is similar to that observed in the simulations of the full-length glycosylated SARS-CoV-2 S protein embedded in a viral membrane ${ }^{18}$ (Figures S5). Principal component analysis (PCA) of the dynamics of the peptide revealed different conformational behaviour of the peptide in the three complexes. When bound to the musclelike receptor, the peptide shows limited dynamical freedom: it explores a restricted conformational space spanned by the first two principal components (Figure S10).

The number of hydrogen bonds between the peptide and the receptors was determined over the simulations (Figure S11). Two more H-bonds are observed in the $\alpha \beta \gamma \delta$ complex than in the $\alpha 4 \beta 2$ and $\alpha 7$ receptors (Figure S11). These additional interactions with the complementary subunit (Figure S11) 
probably contribute to the increased stability of this complex and the more compact conformation of the peptide in the $\alpha \beta \gamma \delta$ receptor.

Analysis of the distribution of the distance between the R682 of the peptide and the conserved aromatic residues forming the aromatic box shows the distinctive behaviour of the peptide bound to different receptors (Figure S12). Interactions with $\mathrm{R} 682, \mathrm{TyrC} 1$ and $\mathrm{TyrC} 2$ are quite frequent in all three complexes, being present more than $60 \%$ of the time. To examine how deeply in the binding pocket the peptide inserts, we monitored the interactions of R682 with $\operatorname{TrpB}$, a residue lining the back wall of the nAChR aromatic box. TrpB ( $\alpha 4 \mathrm{~W} 182, \alpha 7 \mathrm{~W} 171$ and $\alpha \mathrm{W} 173)$ is highly conserved across the nAChR family, and it makes cation- $\pi$ and H-bond interactions with the positively charged group on the ligands. ${ }^{41,42}$ In the $\alpha 4 \beta 2$ and $\alpha \beta \gamma \delta$ complexes, the S-peptide does not extend far into the pocket and interactions between R682 and TrpB are mostly absent (Figure S12). In contrast, in the $\alpha 7$ complex, the peptide binds more deeply into the hydrophobic cavity, adopting conformations that allow not only for the direct contact between R682 and TrpB (Figures S13-S14) but also achieve optimal core-binding interactions (Figure 3). In such configurations, other interactions are present in addition to those with TrpB, namely cation- $\pi$ interactions with TyrC1 and TyrC2 (Figure S14). Although no direct contact between R682 and TyrA is observed, both residues are connected through a H-bond network mediated by Q675 from the S-peptide (Figure S15). This is significant because interactions with TyrA, TrpB, $\mathrm{TyrC} 1$ and $\mathrm{TyrC} 2$ are known to be critical for ligand binding and to modulate gating in the $\alpha 7$ subtype. ${ }^{44-}$ 46
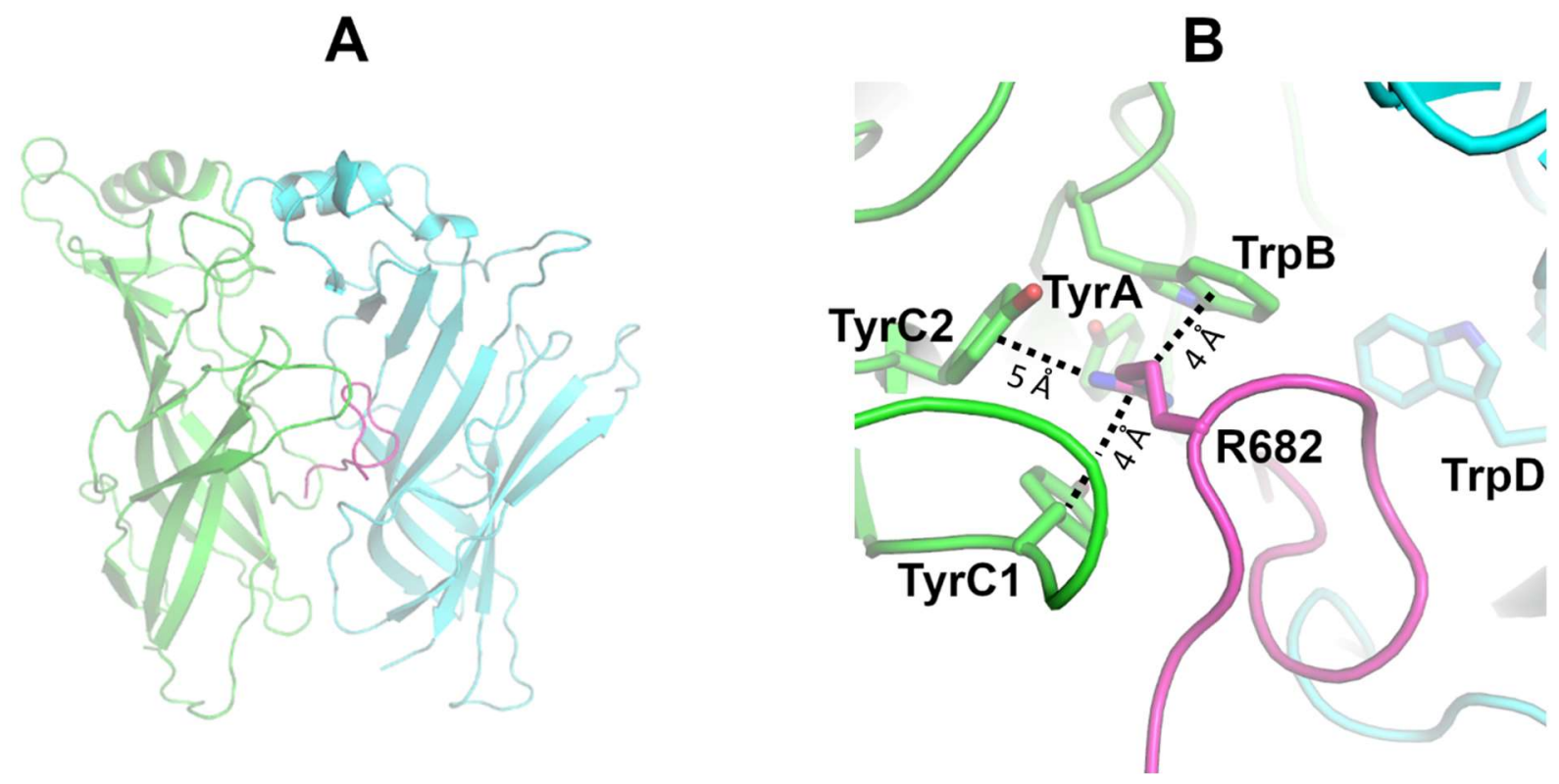

Figure 3. Representative conformation of the $\alpha 7$ complex, in which direct interaction between TrpB and R682 is observed. (A) Overall view of the S-peptide: $\alpha 7$ complex. (B) Closeup view of the R682 interaction region within the aromatic box. The principal and complementary subunits of the $\alpha 7$ receptor are coloured in green and 
cyan, respectively. The S-peptide is highlighted in magenta. Interactions between the guanidinium group of R682 and the aromatic rings of TrpB ( $\alpha 7 \mathrm{~W} 171)$, TyrC1 ( $\alpha 7 \mathrm{Y} 210)$ and TyrC2 ( $\alpha 7 \mathrm{Y} 217)$ are shown with dashed lines.

The binding of a ligand or a peptide can be expected to affect the conformational dynamics of the receptors. To investigate this, the Root Mean Square Fluctuations (RMSF) profiles of the $\mathrm{C}_{\alpha}$ atoms were determined for all three receptors. Distinct dynamic behaviours are observed for the binding site regions (Figures S16-S18). Such differences are mostly located in loops C and F, two structural motifs important for binding and selectivity. ${ }^{45,47,48}$ Loop F shows decreased flexibility in the $\alpha 4 \beta 2$ complex, while loop $\mathrm{C}$ dynamics is more restricted in the muscle-like $\alpha \beta \gamma \delta$ receptor, compared to the other two subtypes.

At the beginning of the simulations, in all the three complexes, loop $\mathrm{C}$ adopted an open conformation due to the steric interference of the peptide. During the simulations, the $\alpha \beta \gamma \delta$ and $\alpha 4 \beta 2$ receptors mostly maintained this open conformation. In the $\alpha 7$ complex, as the peptide moves deeper into the binding pocket, loop C rotates inwards, adopting a semi-closed structure. Loop C capping is known to be important for the anchoring of the ligands into the binding pocket ${ }^{45,47}$ and has been suggested to be indirectly involved in gating. ${ }^{29,49} \mathrm{~A}$ possible relation between loop $\mathrm{C}$ position and ligand activation has also been proposed ${ }^{48}$ with agonists stabilising more compact loop conformations and antagonists disfavouring proper loop closing. Our findings could indicate that the S-peptide may act as an antagonist in the $\alpha \beta \gamma \delta$ and $\alpha 4 \beta 2$ receptors whereas in the $\alpha 7$ receptor it is unclear whether the peptide works as an agonist or antagonist.

A molecular mechanics Poisson-Boltzmann surface area (MM-PBSA) approach ${ }^{50,51}$ was employed to estimate the free energy of binding of the S-peptide to the different receptors (Table S1). MM-PBSA calculations have emerged as an efficient and useful method to determine binding free energies, ${ }^{50,51}$ and are widely used to study protein-ligand interactions in medicinal chemistry, ${ }^{52-54}$ including in drug design for nAChRs. ${ }^{55,56}$ The favourable calculated binding energies suggest stable complex formation between the S-peptide and all three nAChRs (Table S1).

In silico alanine-scanning mutagenesis was performed to identify important residues (referred to as 'hotspots') driving peptide-receptor association (Figures S19-S21). Hot-spots are residues with high energetic contributions to the thermodynamic stability of a given complex ${ }^{57}$ Alanine-scanning methods provide a detailed energy map of a protein-binding interface ${ }^{57}$ Here, we used the fast in silico method, BudeAlaScan, ${ }^{57}$ in which every residue, for both receptor and peptide, is mutated to alanine, and hotspots are determined by the difference between the binding free energies of the mutant and wild-type complexes $\left(\Delta \Delta G_{\text {bind }}\right) .{ }^{57}$ Hot-spots were identified at the interface of the receptor, some of them common to all three subtypes (Figure S22 and Tables S2-S3). In particular, TyrC1 ( $\alpha 4 Y 223, \alpha 7 Y 210, \alpha$ Y214) and the negatively charged residues in the upper part of loop F ( $\beta 2 \mathrm{D} 195, \alpha 7 \mathrm{D} 186, \delta \mathrm{D} 201, \delta \mathrm{E} 203)$ 
strongly stabilise the complex. In the human $\alpha 7 \mathrm{nAChR}$, the substitution of several key agonist-binding residues within the aromatic box, namely TyrA ( $\alpha 7 \mathrm{Y} 115), \operatorname{TyrC1}(\alpha 7 \mathrm{Y} 210), \operatorname{TrpB}(\alpha 7 \mathrm{~W} 171)$ and TrpD ( $\alpha$ W 77), by alanine is also predicted to destabilise the interface between the peptide and the receptor. Concerning residues in the peptide, Y674, R682 and R685 are the major contributors to stabilizing the interface (Figure S23). Overall, this analysis reinforces the critical role of R682 in binding to nAChRs. In summary, the findings reported here support the hypothesis that the SARS-CoV-2 S protein can interact with nAChRs. Our calculations indicate stable binding of the $\mathrm{S}$ protein to these receptors through a region adjacent to the furin cleavage site and corresponding to the Y674-R685 loop. They also show apparent subtype-specific interactions and dynamics for the Y674-R685 region. COVID-19 is known to cause a range of neurological, ${ }^{58,59}$ muscular, ${ }^{38}$ and respiratory ${ }^{60}$ symptoms, and these predicted interactions may be relevant to understand the pathophysiology associated with this disease.

Our results indicate that the Y674-R685 region from the S protein has affinity for nAChRs in general. The region in the S protein responsible for the binding to nAChRs harbours the PRRA motif and shares high sequence similarity with neurotoxins known to be nAChRs antagonists. In particular, the guanidinium group of R682 is the key anchoring point to the binding pocket, where it forms several interactions with the residues that form the aromatic box. Analysis of the structure and dynamics of the full-length glycosylated S protein shows that the Y674-R685 region protrudes outside the glycan shield, and is flexible, showing that it is accessible to bind to nAChRs (and to other receptors such as neuropilins ${ }^{25}$ ). Modelling the interaction between the full-length S protein and $\mathrm{nAChRs}$ indicates that association is possible with the proteins in a non-parallel orientation to one another. It has been shown experimentally that not all S proteins protrude straight from the viral surface and a tilt angle up to $60^{\circ}$ relative to the normal axis of the membrane is observed. ${ }^{61,62}$ This apparent flexibility of the S-protein would facilitate binding to host nAChRs.

In the $\alpha 4 \beta 2$ and $\alpha \beta \gamma \delta$ complexes, the conformational dynamics of the bound Y674-R685 peptide are compatible with the hypothesis of it acting as an antagonist: it forces the loop $\mathrm{C}$ to adopt an open conformation and prevents the formation of key interactions within the binding pocket. Intriguingly, in the $\alpha 7$ complexes, the peptide adopts binding modes that allow for the establishment of strong interactions within the aromatic box, thus raising the question of whether, in this subtype, it promotes gating. This is important because activation of $\alpha 7 \mathrm{nAChR}$ triggers anti-inflammatory signalling mechanisms in inflammatory cells, leading to a decrease in cytokine production, which may have relevance in understanding COVID-19 pathology. If nicotine does indeed prove to have any clinical value, it is likely that it would be due to interfering with the association with nAChRs. If so, nicotine analogues (e.g. smoking cessation agents) such as varenicline ${ }^{63}$ cytisine ${ }^{64}$ and cytisine derivatives ${ }^{30}$ could also find useful application for COVID-19. 
Given the promising results presented here, structural, mutational and single-channel studies will be of interest to test the importance of the interactions of the S protein from SARS-CoV-2 with nAChRs, and the potential relevance of these interactions to pathology and infectivity in COVID-19.

\section{References}

1. Yan R, Zhang Y, Li Y, Xia L, Guo Y, Zhou Q. Structural basis for the recognition of SARSCoV-2 by full-length human ACE2. Science. 2020;367:1444-1448.

2. Rothan HA, Byrareddy SN. The epidemiology and pathogenesis of coronavirus disease (COVID-19) outbreak. J Autoimmun. 2020;109:102433.

3. Lake MA. What we know so far: COVID-19 current clinical knowledge and research. Clin Med (Lond). 2020;20:124-127.

4. Dong E, Du H, Gardner L. An interactive web-based dashboard to track COVID-19 in real time. Lancet Infect Dis. 2020;20:533-534.

5. Huang C, Wang Y, Li X, et al. Clinical features of patients infected with 2019 novel coronavirus in Wuhan, China. Lancet. 2020;395:497-506.

6. Farsalinos K, Barbouni A, Niaura R. Systematic review of the prevalence of current smoking among hospitalized COVID-19 patients in China: could nicotine be a therapeutic option? Intern Emerg Med. 2020.

7. Guan WJ, Ni ZY, Hu Y, et al. Clinical Characteristics of Coronavirus Disease 2019 in China. N Engl J Med. 2020;382:1708-1720.

8. Liu W, Tao ZW, Wang L, et al. Analysis of factors associated with disease outcomes in hospitalized patients with 2019 novel coronavirus disease. Chin Med J (Engl). 2020;133:10321038 .

9. Gonzalez-Rubio J, Navarro-Lopez C, Lopez-Najera E, et al. Cytokine Release Syndrome (CRS) and Nicotine in COVID-19 Patients: Trying to Calm the Storm. Front Immunol. 2020;11:1359.

10. Cohen B, Nichols A, Grant S, et al. Successful Cessation Programs that Reduce Comorbidity May Explain Surprisingly Low Smoking Rates Among Hospitalized COVID-19 Patients. preprint (DOI:1032388/WURFH0). 2020.

11. Changeux J, Amoura Z, Rey F, Miyara M. A nicotinic hypothesis for Covid-19 with preventive and therapeutic implications. CR Biol. 2020;343:33-39.

12. Wonnacott S. Presynaptic nicotinic ACh receptors. Trends in Neurosci. 1997;20:92-98.

13. Gharpure A, Noviello CM, Hibbs RE. Progress in nicotinic receptor structural biology. Neuropharmacology. 2020;171:108086.

14. Cecchini M, Changeux JP. The nicotinic acetylcholine receptor and its prokaryotic homologues: Structure, conformational transitions \& allosteric modulation. Neuropharmacology. 2015;96:137-149.

15. Thompson AJ, Lester HA, Lummis SC. The structural basis of function in Cys-loop receptors. Q Rev Biophys. 2010;43:449-499.

16. Nemecz A, Prevost MS, Menny A, Corringer PJ. Emerging Molecular Mechanisms of Signal Transduction in Pentameric Ligand-Gated Ion Channels. Neuron. 2016;90:452-470.

17. Changeux JP. The nicotinic acetylcholine receptor: a typical 'allosteric machine'. Philos Trans R Soc Lond B Biol Sci. 2018;373.

18. Casalino L, Gaieb Z, Dommer A, et al. Shielding and Beyond: The Roles of Glycans in SARSCoV-2 Spike Protein.2020, pre-print (DOI: 10.1101/2020.06.11.146522).

19. Rahman MM, Teng J, Worrell BT, et al. Structure of the Native Muscle-type Nicotinic Receptor and Inhibition by Snake Venom Toxins. Neuron. 2020;106:952-962.

20. Bosch BJ, van der Zee R, de Haan CA, Rottier PJ. The coronavirus spike protein is a class I virus fusion protein: structural and functional characterization of the fusion core complex. $\mathrm{J}$ Virol. 2003;77:8801-8811. 
21. Walls AC, Park YJ, Tortorici MA, Wall A, McGuire AT, Veesler D. Structure, Function, and Antigenicity of the SARS-CoV-2 Spike Glycoprotein. Cell. 2020;181:281-292.e286.

22. Davidson AD, Williamson MK, Lewis S, et al. Characterisation of the transcriptome and proteome of SARS-CoV-2 using direct RNA sequencing and tandem mass spectrometry reveals evidence for a cell passage induced in-frame deletion in the spike glycoprotein that removes the furin-like cleavage site. pre-print (DOI:101101/20200322002204). 2020.

23. Apellániz B, Huarte N, Largo E, Nieva J. The Three Lives of Viral Fusion Peptides. In: Chemistry and Physics of Lipids. Elsevier Ireland Ltd; 2014:40-55.

24. Hoffmann M, Kleine-Weber H, Pöhlmann S. A Multibasic Cleavage Site in the Spike Protein of SARS-CoV-2 Is Essential for Infection of Human Lung Cells. Mol Cell. 2020;78:779784.e775.

25. Daly J, Simonetti B, Antón-Plágaro C, et al. Neuropilin-1 is a host factor for SARS-CoV-2 infection. pre-print (DOI: 101101/20200605134114). 2020.

26. Cheng MH, Zhang S, Porritt RA, Arditi M, Bahar I. An insertion unique to SARS-CoV-2 exhibits superantigenic character strengthened by recent mutations. pre-print (DOI: 101101/20200521109272). 2020.

27. Farsalinos K, Eliopoulos E, Leonidas D, Papadopoulos G, Tzartos S, Poulas K. Molecular modelling and docking experiments examining the interaction between SARS-CoV-2 spike glycoprotein and neuronal nicotinic acetylcholine receptors. pre-print (DOI: 1020944/preprints2020050365v1). 2020.

28. Oliveira ASF, Shoemark DK, Campello HR, Gallagher T, Sessions RB, Mulholland AJ. Identification of the initial steps in signal transduction in the $\alpha 4 \beta 2$ nicotinic receptor: insights from equilibrium and nonequilibrium simulations. Structure. 2019;27:1171-1183.

29. Oliveira A, Edsall C, Woods C, et al. A general mechanism for signal propagation in the nicotinic acetylcholine receptor family. J Am Chem Soc. 2019;141:19953-19958.

30. Campello HR, Del Villar SG, Honraedt A, et al. Unlocking Nicotinic Selectivity via Direct CH Functionalisation of (-)-Cytisine. Chem. 2018;4:1710-1725.

31. Dineley KT, Pandya AA, Yakel JL. Nicotinic ACh receptors as therapeutic targets in CNS disorders. Trends Pharmacol Sci. 2015;36:96-108.

32. Haydar S, Dunlop J. Neuronal Nicotinic Acetylcholine Receptors - Targets for the Development of Drugs to Treat Cognitive Impairment Associated with Schizophrenia and Alzheimer's Disease. Cur Top Med Chem. 2010;10:144-152.

33. Martelli D, Farmer DG, Yao ST. The splanchnic anti-inflammatory pathway: could it be the efferent arm of the inflammatory reflex? Exp Physiol. 2016;101:1245-1252.

34. Tracey KJ. The inflammatory reflex. Nature. 2002;420:853-859.

35. Maturo MG, Soligo M, Gibson G, Manni L, C N. The greater inflammatory pathway-high clinical potential by innovative predictive, preventive, and personalized medical approach. EPMA J 2020;11:1-16

36. Manni L, Tieri P, Soligo M. A contribution to the hypothesis of nicotinic challenge as therapeutic option for COVID-19 patients. pre-print (DOI: 1032388/UJX3KN2). 2020.

37. Unwin N. Nicotinic acetylcholine receptor and the structural basis of neuromuscular transmission: insights from Torpedo postsynaptic membranes. Q Rev Biophys. 2013;46:283322.

38. Cipollaro L, Giordano L, Padulo J, Oliva F, Maffulli N. Musculoskeletal symptoms in SARSCoV-2 (COVID-19) patients. J Orthop Surg Res. 2020;15:178.

39. Wang GK, Schmidt J. Primary structure and binding properties of iodinated derivatives of alpha-bungarotoxin. J Biol Chem. 1980;255:11156-11162.

40. Sali A. Comparative Protein Modeling by Satisfaction of Spatial Restraints. Mol Med Today. 1995a; $1: 270-277$.

41. Dougherty DA. Cys-loop neuroreceptors: structure to the rescue? Chem Rev. 2008;108:16421653.

42. Corringer PJ, Poitevin F, Prevost MS, Sauguet L, Delarue M, Changeux JP. Structure and pharmacology of pentameric receptor channels: from bacteria to brain. Structure. 2012;20:941956. 
43. Morales-Perez CL, Noviello CM, Hibbs RE. X-ray structure of the human alpha 4 beta 2 nicotinic receptor. Nature. 2016;538:411-415.

44. Williams DK, Stokes C, Horenstein NA, Papke RL. Differential regulation of receptor activation and agonist selectivity by highly conserved tryptophans in the nicotinic acetylcholine receptor binding site. J Pharmacol Exp Ther. 2009;330:40-53.

45. Puskar NL, Xiu X, Lester HA, Dougherty DA. Two neuronal nicotinic acetylcholine receptors, alpha4beta4 and alpha7, show differential agonist binding modes. J Biol Chem. 2011;286:14618-14627.

46. Van Arnam EB, Blythe EE, Lester HA, Dougherty DA. An unusual pattern of ligand-receptor interactions for the $\alpha 7$ nicotinic acetylcholine receptor, with implications for the binding of varenicline. Mol Pharmacol. 2013;84:201-207.

47. Horenstein NA, McCormack TJ, Stokes C, Ren K, Papke RL. Reversal of agonist selectivity by mutations of conserved amino acids in the binding site of nicotinic acetylcholine receptors. J Biol Chem. 2007;282:5899-5909.

48. Nys M, Kesters D, Ulens C. Structural insights into Cys-loop receptor function and ligand recognition. Biochem Pharmacol. 2013;86:1042-1053.

49. Purohit $\mathrm{P}$, Auerbach A. Loop $\mathrm{C}$ and the mechanism of acetylcholine receptor-channel gating. $\mathrm{J}$ Gen Physiol. 2013;141:467-478.

50. Wang C, Greene D, Xiao L, Qi R, Luo R. Recent Developments and Applications of the MMPBSA Method. Front Mol Biosci. 2017;4:87.

51. Genheden S, Ryde U. The MM/PBSA and MM/GBSA methods to estimate ligand-binding affinities. Expert Opin Drug Discov. 2015;10:449-461.

52. Slynko I, Schmidtkunz K, Rumpf T, et al. Identification of Highly Potent Protein Kinase CRelated Kinase 1 Inhibitors by Virtual Screening, Binding Free Energy Rescoring, and in vitro Testing. ChemMedChem. 2016;11:2084-2094.

53. Evers A, Klabunde T. Structure-based drug discovery using GPCR homology modeling: successful virtual screening for antagonists of the alpha1 A adrenergic receptor. J Med Chem. 2005;48:1088-1097.

54. Raza S, Ranaghan KE, van der Kamp MW, Woods CJ, Mulholland AJ, Azam SS. Visualizing protein-ligand binding with chemical energy-wise decomposition (CHEWD): application to ligand binding in the kallikrein-8 S1 Site. J Comput Aided Mol Des. 2019;33:461-475.

55. Grazioso G, Pomè DY, Matera C, et al. Design of novel alpha7-subtype-preferring nicotinic acetylcholine receptor agonists: application of docking and MM-PBSA computational approaches, synthetic and pharmacological studies. Bioorg Med Chem Lett. 2009;19:63536357.

56. Grazioso G, Cavalli A, De Amici M, Recanatini M, De Micheli C. Alpha7 nicotinic acetylcholine receptor agonists: prediction of their binding affinity through a molecular mechanics Poisson-Boltzmann surface area approach. J Comput Chem. 2008;29:2593-2602.

57. Ibarra AA, Bartlett GJ, Hegedüs Z, et al. Predicting and Experimentally Validating Hot-Spot Residues at Protein-Protein Interfaces. ACS Chem Biol. 2019;14:2252-2263.

58. Ellul MA, Benjamin L, Singh B, et al. Neurological associations of COVID-19. Lancet Neurol. 2020.

59. Paterson RW, Brown RL, Benjamin L, et al. The emerging spectrum of COVID-19 neurology: clinical, radiological and laboratory findings. Brain. 2020.

60. Yuki K, Fujiogi M, Koutsogiannaki S. COVID-19 pathophysiology: A review. Clin Immunol. 2020;215:108427.

61. Yao H, Song Y, Chen Y, et al. Molecular architecture of the SARS-CoV-2 virus. pre-print (DOI: 101101/20200708192104). 2020.

62. Ke Z, Oton J, Qu K, et al. Structures, conformations and distributions of SARS-CoV-2 spike protein trimers on intact virions. pre-print (DOI: 101101/20200627174979). 2020.

63. Hays JT, Ebbert JO. Varenicline for tobacco dependence. N Engl J Med. 2008;359:2018-2024.

64. Etter JF. Cytisine for smoking cessation: a literature review and a meta-analysis. Arch Intern Med. 2006;166:1553-1559. 


\section{Acknowledgements}

AJM and ASFO thank EPSRC (grant number EP/M022609/1) and Elizabeth Blackwell Institute for Health Research, University of Bristol, for financial support (Elizabeth Blackwell Institute Rapid Response Funding Call (COVID-19). MD simulations were carried out using the computational facilities of the Advanced Computing Research Centre, University of Bristol (http://www.bris.ac.uk/acrc) and Oracle Public Cloud Infrastructure (https://cloud.oracle.com/en_US/iaas) under an award for COVID-19 research. We thank Dr Simon Bennie and Dr Jonathan Barnoud for help with the Cluster-in-the-cloud tool and the creation of a fully elastic and scalable cluster on the Oracle Cloud. AJM, ASFO, RBS and DKS also thank EPSRC for provision of ARCHER HPC time through HECBioSim (HECBioSim.ac.uk) under a COVID-19 award. RA acknowledges support from NIH (GM132826), NSF RAPID (MCB-2032054), an award from the RCSA Research Corp. and a UC San Diego Moore's Cancer Center 2020 SARS-COV-2 seed grant. LC is funded by a Visible Molecular Cell Consortium fellowship. RA, LC and ZG thank the Texas Advanced Computing Center (TACC) Frontera team and acknowledge computer time made available through a Director's Discretionary Allocation (made possible by the NSF award OAC-1818253). 